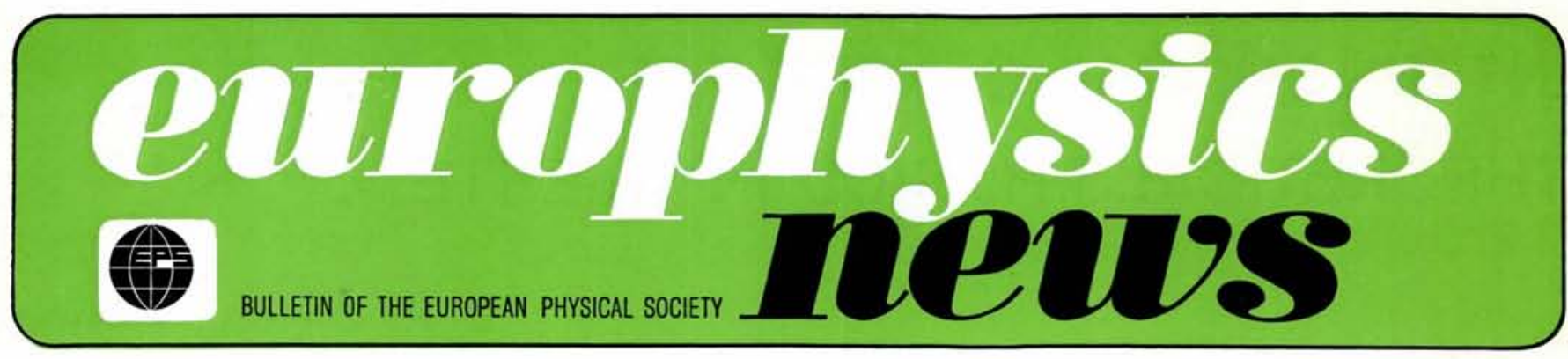

J.A.

\title{
EPS Conferences
}

\section{Where Do We Stand?}

The EPS Advisory Committee on Conferences has been taking a look at how the system of organizing and sponsoring conferences is working and whether members think that the present position could be improved. Neglecting purely national conferences, between $30 \%$ and $40 \%$ of all international conferences on physics organized in Europe are either organized directly by EPS Divisions or Sections, or are sponsored by EPS. Is this good, bad, or indifferent? On the whole it seems that the general opinion is that in view of the comparative youth of EPS, this is a pretty reasonable showing. It is improbable that $100 \%$ would ever be achieved or would even be desirable as there will always be special cases where the need for a conference is felt by an individualistic group but for some reason it does not conform to the EPS structures or rules. It is also not always clear where physics ends and other disciplines begin so we must leave some room for the other scientific disciplines to manoevre. All the same, there is a margin for growth as more and more organizers acknowledge the value of European coordination.

Not all the present regulations are appreciated. Emerging from the suggestions received from the EPS Divisions and Sections is a clear objection to the capitation fee that is levied on EPS organized conferences so that funds can be made available for helping notably the younger members of the physics community to attend conferences which otherwise would be out of their reach. Is though a capitation fee necessarily the best way of doing this? There are strong doubts.
It is clearly desirable for conference organizers to be in a position to offer help to students as well as travelling expenses to special speakers, but would this not come better out of a different fund? We all understand that there is no magic pot out which such funds can be provided but how to feed the pot is now a subject of renewed debate.

One way out is to integrate the European Conference Abstracts into the scheme. At present, abstracts of papers presented at only some of the EPS organized conferences appear in the ECA Series, which diminishes the value of this publication and, at the same time, reduces the circulation that the conference abstracts would otherwise have and excludes any share in the publishing profits that should accrue. There is clearly an opportunity here for mutual help. Abstracts have (in general) to be produced ; making them part of the Series would enhance the value of the Series and so its profitability and reduce the unit cost of the abstracts thereby providing a source of revenue to feed the Conference Fund. The new editor of the ECA Series, L. van Gerven, has some strong views on this subject.

A call for better discipline will not be unexpected. Late finalization of proposals which might clash with other conferences, this applies especially to EPS organized conferences, where a one-year lead time is absolutely necessary and late application for sponsorship, all contribute to making the coordination system less efficient that it might be. This is not a bureaucratic demand for standardization, but a necessary pre-requisite for the conference programme to be tailored as far as possible to the needs of EPS members and European physicists in general.

It is also time to get a little tougher in regard to fees. In cases of cosponsorship, there may be difficulties, but for EPS organized conferences it seems clear that Individual Ordinary Members of EPS must get special treatment. Even for sponsored conferences, it should be normal that our IOMs do receive some rebate, as the EPS label is not a sycophancy but a mark of quality that administrative bodies responsible for funding participants or subventioning the organisation are using more and more as a determinant factor when establishing their attitude. From now on, EPS organized conferences will list three registration fees - EPS Members, Nonmembers and Students, while sponsored conferences will be expected to follow the same line accepting that there may be other bodies also receiving favourable treatment.

\section{Contents}

EPS Conferences:

Where Do We Stand? . . . 1

ICTP in Trieste

1977 Nobel Prize in Physics . . 5

EPS Conference Reports

Workshops of the Solar

Physics Section

Phase Transitions in Bulk

Polvmers

Fusion Oriented

Plasma Physics

Laser Interactions with Solids

JET Decision Taken .

ESO Comet

Society News
2

7

8

8

8

10

Europhysics News is published monthly by the European Physical Society. (c) 1977. Reproduction rights reserved. 